Bull. Egypt. Soc. Physiol. Sci. 38(1), 1-12

\author{
Bull. of Egyp. Soc. Physiol. Sci. \\ (Official Journal of Egyptian Society for Physiological Sciences) \\ (pISSN: 1110-0842; eISSN: 2356-9514)
}

\title{
Assessment of the Metabolic Mediators: Fatty Acid Synthase, Lactate Dehydrogenase and miR-181a as Potential Diagnostic Markers in Colorectal Cancer Patients
}

\author{
Amany I. Youssef ${ }^{1}$, Mohamed Abdel Rahman Ahmed ${ }^{2}$, Mohamed Samir ${ }^{3}$, Ibrahim \\ Mohammed Mansour ${ }^{4}$, Mostafa Aly El Naggar ${ }^{5}$, Tarek S. El Sewedy ${ }^{1}$ \\ ${ }^{1}$ Department of Applied Medical Chemistry, Medical Research Institute, Alexandria University. \\ ${ }^{2}$ Department of Clinical Pathology, Military Academy of Medicine, Ale xandria Armed Fo rces Hospital. \\ ${ }^{3}$ Experimental and clinical surgery department, Medical Research Institute, Ale xandria University. \\ ${ }^{4}$ Medical Specialist, Faculty of Medicine and Health Sciences, Sanaa university, Yemen. \\ ${ }^{5}$ Department of Cancer Management and Research, Medical Research Institute, Alexandria University.
}

Received: 18 June 2017

Accepted: 20 August 2017

A vailable online: 1 Jan 2018

\section{Keywords}

Colorectal cancer,

Metabolic mediators.

Fatty acid Synthase.

Lactate dehydrogenase.

miR-181a.

\section{Abstract}

Background: Cancer cells support their growth and invasion by rewiring their metabolism. Therefore our aim was to explore the value of some metabolic mediators such as serum Fatty Acid Synthase (FASN) level and Lactate Dehydrogenase (LDH) activity as well as CEA, CA 19-9 and plasma miR-181a levels as diagnostic markers and evaluating their relationship to the clin icopathological features in colorectal cancer (CRC) patients. The association of fasting blood sugar (FBS) and triglyceride (TG) levels as risk factors for colorectal cancer was also assessed. The study was conducted on 70 colorectal cancer patients and 30 controls. Results: CEA, CA199, FASN and miR-181a levels were significantly higher in sera of CRC patients compared to controls. miR-181a levels increased significantly according to stage and grade while CA 19-9 increased significantly with grade not stage. LDH activity didn't show significant difference between CRC patients and control except for stage IV. CA19-9 and FASN were significantly increased among males while miR-181a was significantly elevated in female patients. None of the markers showed significant difference according to tumour site. Weak positive and negative correlations were observed between FASN and TG, between LDH and FBS respectively. Moreover, moderate and strong positive correlations were observed between miR-181a and FBS, between CEA and CA19-9 respectively. Conclusion: FASN showed the best diagnostic value with $96 \%$ sensitivity and $95 \%$ specificity followed by miR-181a with $95 \%$ sensitivity and $90 \%$ specificity; both were superior to LDH, CEA and CA 19-9. Moreover, miR-181a had the best association with stage and grade compared to all other studied markers. 


\section{Introduction:}

Colorectal cancer (CRC) is the third most common cancer in men and the second in women with about one million new cases being diagnosed annually worldwide (1). Epidemiological data showed a variation in CRC incidence and mortality rates among different geographic areas and populations, this might be attributable to the exposure to variable risk factors, different dietary and lifestyles. Globally, about $55 \%$ of the CRC cases occur in developed countries; nevertheless, incidence rates has significantly increased in developing countries especially among low socioeconomic communities due to modifiable risk factors such as unhealthy diet and obesity as well as costly screening costs. In Egypt CRC is ranked as the $8^{\text {th }}$ cancer with incidence rate accounting for $4 \%$ in men and $3.5 \%$ in women (2, 3).

Colonoscopy plays a central role in the diagnosis of CRC, however it is considered a costly inconvenient and invasive technique that cannot be practiced routinely for asymptomatic individuals. Therefore, cheap, blood based diagnostic and noninvasive tests for early detection of CRC remains a major challenge to physicians as it is only way towards a lower mortality and a better treatment outcome (4). Unfortunately, in many cases the CRC is diagnosed only after the patients are already at an advanced stage CRC (5).

Cancer cells are characterized by an altered metabolism in order to support the rapid proliferation, growth and invasion required by malignant cells (6). Therefore, assessment of potential metabolic mediators as biomarkers that can be used for the early detection of CRC is becoming an area of interest, especially that traditional tumor markers such as Carcinoembryonic Antigen (CEA) and Carbohydrate Antigen 19-9 (CA19-9) has their limitations of a non satisfactory sensitivity and specificity especially in the diagnosis of early stages of CRC $(7,8)$. The altered metabolism of CRC cells involves an altered carbohydrate, lipid, amino acid and nucleotide metabolism (9).

Carbohydrate metabolic perturbations include a distinct cancerous cell metabolic feature that is increased aerobic Glycolysis or the "Warburg effect", where cells use Glycolys is as a main source of energy supply even in the presence of abundant levels of oxygen (10).

Glycolysis related enzymes are frequently over expressed or show increased activity in cancer cells $(11,12)$. Hyper-production of lactate by Lactate dehydrogenase (LDH) promotes cell motility, impairs function of immune system and when secreted out of the cell it promote angiogenesis $(13,14)$.

On the other hand, lipid metabolic perturbations include lipogenic enzymes such as Fatty Acid Synthase (FASN) which is highly elevated in serum of numerous human cancers. FASN catalyzes the synthesis of long-chain fatty acids used for membrane assembly, prote in modification and as a source of energy (15-18). Moreover, its elevated expression levels were reported to correlate with poor prognosis and tumour aggressiveness (19).

Altered carbohydrate and lipid metabolism might lead to obesity which is one of the components of the metabolic syndrome that has been associated with colon, liver and gastric cancers (20). Increased circulating levels of 
triglycerides and glucose were also reported to be associated with cancer $(21,22)$.

Recently, a large number of micro-RNAs (miRNAs) were identified to play a role in cancer through regulation of metabolism and other actions (23). miR-181a aberrant expression was reported in several types of cancers, it is down regulated in Glioblastoma and non small cell lung cancer (24) While up-regulated in ovarian, breast and liver cancer (25-27). It was also reported that miR-181a plays an important role in $\mathrm{CRC}$ metabolic reprogramming (28).

The aim of the present study was to evaluate the potential value of metabolic mediators such as LDH activity, FASN, plasma miR-181a as well as CEA and CA19-9 levels as diagnostic markers for colorectal cancer. The potential relationship of these markers with the clinicopathological features of the tumour was also assessed.

\section{Subjects and methods:}

The present study was carried out on a total of 100 participants; 70 patients diagnosed with CRC (from 32 to 78 years old), were admitted to the Experimental and Clinical Surgery Department at the Medical Research Institute Hospital, Alexandria University, between January 2015 to February 2017 and 30 control healthy participants with no family history of CRC or inflammatory bowel disease, with age ranging from 27 to 50 years old. Inclusion crite ria: patients with CRC as diagnosed by colonoscopy and histopathological examinations. Exclusion criteria: previous gastrointestinal tract surgery, inflammatory bowel diseases, patients with cancers in another organs and/or currently receiving chemotherapy.
All protocols of the study were reviewed and approved by the ethical committee of the Medical Research Institute (IORG 0008812), Alexandria University and a written informed consent was obtained from all participants.

All participants were subjected to the followings laboratory investigations: FBS, TG, CEA and CA 19-9, serum FASN level, LDH activity and quantification of plasma miR-181a.

\section{Methods:}

\section{Blood analys is :}

$5 \mathrm{ml}$ venous blood was withdrawn from all participants, $2 \mathrm{ml}$ was collected on EDTA coated tubes to separate plasma and $3 \mathrm{ml}$ were left for 15 $\mathrm{min}$ at room temperature before centrifugation to separate serum. Blood analys is including FBS, TG and LDH activity were performed by Cobas ${ }^{\circledR} 6000$ c501 Clinical Chemistry Analyzer (Roche Diagnostics GmbH, Mannheim, Germany), while CEA and CA19-9 by the Roche Cobas ${ }^{\circledR}$ e601 electrochemical luminescence analyzer. Measurement of serum FASN level was performed using ELISA kit (cloud-clone Corp, USA) according to the manufacturer's instructions.

\section{Relative quantitation of miR-181a by Real- Time PCR:}

Total plasma RNA was isolated using the miRNeasy Kit (QIAGEN, Germany), reverse transcribed to cDNA using the TaqMan® MicroRNA Reverse Transcription Kit (Applied Biosystems, USA). Quantitative real-time PCR was performed using the TaqMan® Universal PCR Master Mix and TaqMan® miRNA assay using the following TaqMan probes: hsa- miR181a (ID 000480) and cel-miR-39 (ID\#000200) as internal control. All methods were performed 
according to the kits manufacturer's instructions. The real-time PCR was performed using the StepOnePlus Real-Time PCR System (Applied Biosystems, USA), reaction were done in a final volume of $20 \mu \mathrm{l}(10 \mu \mathrm{l}$ of TaqMan Master Mix, $1.33 \mu \mathrm{l}$ of cDNA, $1 \mu \mathrm{l}$ of $20 \mathrm{X}$ TaqMan miRNA assay and 7.67 nuclease free water) and amplification conditions were $50{ }^{\circ} \mathrm{C}$ for 2 minutes, followed by holding at $95{ }^{\circ} \mathrm{C}$ for 10 minutes then 40 cycles at $95^{\circ} \mathrm{C}$ for 15 seconds and $60{ }^{\circ} \mathrm{C}$ for 60 seconds. $\mathrm{C}_{\mathrm{T}}$ values were calculated using the StepOne v2.2.1 software (Applied Biosystems, USA). The comparative cycle threshold $\left(\Delta \mathrm{C}_{\mathrm{T}}\right)$, $\Delta \Delta \mathrm{C}_{\mathrm{T}}$ and the fold change $=2^{-\Delta \Delta \mathrm{CT}}$ was calculated by Microsoft Excel as described by Livak K. et al. (29).

\section{Statistical analysis:}

Statistical analys is was done using the Statistical Package for Social Sciences version 20 (SPSS Inc, Chicago, ILL Company). Quantitative data were expressed as mean $\pm \mathrm{SD}$ for normally distributed or median for abnormally distributed data, nonparametric tests were used to compare medians across groups. Mann-Whitney test was used for comparison between two groups when the values were abnormally distributed. The significant measurements between different groups were determined by Duncan multiple range test. Spearman's rank correlation coefficient was used to test potential correlations, Cut-off values of tumor markers were determined according to the receiver-operator characteristic (ROC) analysis. $\mathrm{P}$ values $\leq 0.05$ were considered significant.

\section{Results :}

Demographic and clinical characteristics of control and CRC patients are presented in Table (1) and clinicopathological characteristics of patients are presented in Table (2).

BMI was significantly lower in CRC patients compared to controls $(\mathrm{P}=0.002)$, FBS levels were significantly higher in CRC patients $(\mathrm{P}=0.003)$ however the levels were within the normal range, TG levels did not show significant difference $(\mathrm{P}=0.32)$. A modest association for both FBS and TG levels was observed (O.R 1.68, CI 0.071-0.65) and (O.R 1.77, CI 0.11- 0.79) respectively. Table (1).

Serum concentrations of CEA, CA19-9, FASN and miR-181a were significantly higher in CRC patients compared with healthy controls, $(\mathrm{P}=$ 0.001, $\mathrm{P}=0.011, \mathrm{P}=0.001, \mathrm{P}=0.0001)$ respectively. However, overall serum LDH activity did not show a significant difference between patients and control $(\mathrm{P}=0.920)$. Table (3).

When CRC patients were subdivided according to gender, CA19-9 and FASN were significantly higher in male than female patients $(\mathrm{P}=0.031$ and 0.014) respectively, while miR-181a was significantly higher in female patients $(\mathrm{P}=0.0002)$. On the other hand, none of the studied markers showed significant difference with tumour location. Table (3).

Serum CEA, CA19-9 and FASN levels showed a significant difference between certain, but not all CRC stages; however there was no clear progressive increasing or decreasing pattern associated with the tumour stage, Table (4). Serum LDH levels showed a significant high increase in advanced stage IV patients compared to all other stages and control. On the other hand, miR-181a levels were significantly increased with the tumour stage, Table (4). There was no association between 
tumour grade and CA19-9, FASN and LDH. However, both CEA and miR-181a showed a significantly higher level at higher tumour grade, Table (5). The Diagnostic accuracy of the studied markers were evaluated using ROC curve which indicated that the CEA had $90 \%$ sensitivity and $85 \%$ specificity, CA19-9 had $92 \%$ sensitivity and $88 \%$ specificity, FASN had $96 \%$ sensitivity and 95\% specificity and finally, miR-181a had $95 \%$ sensitivity and 90\% specificity Figure (1) and
Table(6). The correlation between all studied parameters in CRC patients was also analyzed. The statistically significant correlations are shown in Figure (2); a weak positive correlation between FASN and TG $(r=0.281, \mathrm{p}=0.018)$, a weak negative correlation between LDH and FBS ( $\mathrm{r}=$ 0.295, $\mathrm{p}=.013)$, a moderate positive correlation between miR-181a and FBS $(r=0.475, p=0.0001)$ and a strong positive correlation between CEA and CA19-9 $(r=0.740, p=0.0001)$ (figure 2).

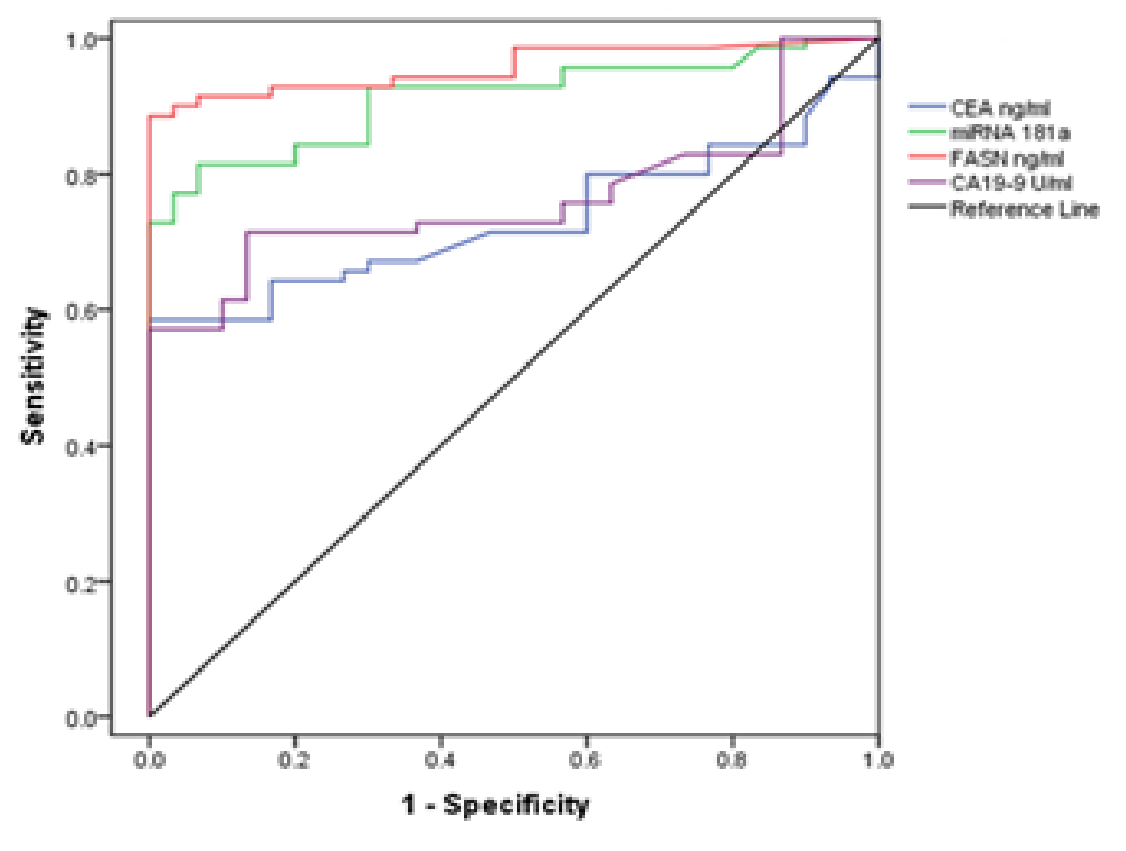

Figure (1): Multiple ROC curves for the evaluation of diagnostic efficiencies of markers

Table (1): Demographic and clinical features for controls $(n=30)$ and patients $(n=70)$

\begin{tabular}{|c|c|c|c|c|}
\hline Variable & $\begin{array}{c}\text { Control } \\
\mathbf{n}(\%)\end{array}$ & $\begin{array}{c}\text { Patients } \\
\mathbf{n}(\boldsymbol{\%})\end{array}$ & OR $^{\#}$ & CI $^{\#}$ \\
\hline Male & $12(40.0 \%)$ & $30(42.9 \%)$ & -- & -- \\
\hline Female & $18(60.0 \%)$ & $40(57.1 \%)$ & & \\
\hline Age $^{(}$ & $43.3 \pm 6.8$ & $57.3 \pm 12.4$ & -- & -- \\
\hline BMI $^{\Theta}$ & $27.8 \pm 5.4$ & $24.0 \pm 3.6^{*}$ & -- & -- \\
\hline FBS (mg/dl) ${ }^{(}$ & $91.3 \pm 4.8$ & $104.6 \pm 23.4 *$ & 1.68 & $0.071-0.65$ \\
\hline TG (mg/dl) ${ }^{(}$ & $103.8 \pm 60.2$ & $134.5 \pm 66.3$ & 1.77 & $0.11-0.79$ \\
\hline
\end{tabular}

${ }^{\circledR}$ Values expressed as mean \pm standard deviation; $n=$ Total number; *significant difference as compared with control; significant $\mathrm{P}$ values $\leq 0.05 ;{ }^{\#} \mathrm{OR}$, odds ratio; $\mathrm{CI}$, confidence interval. 

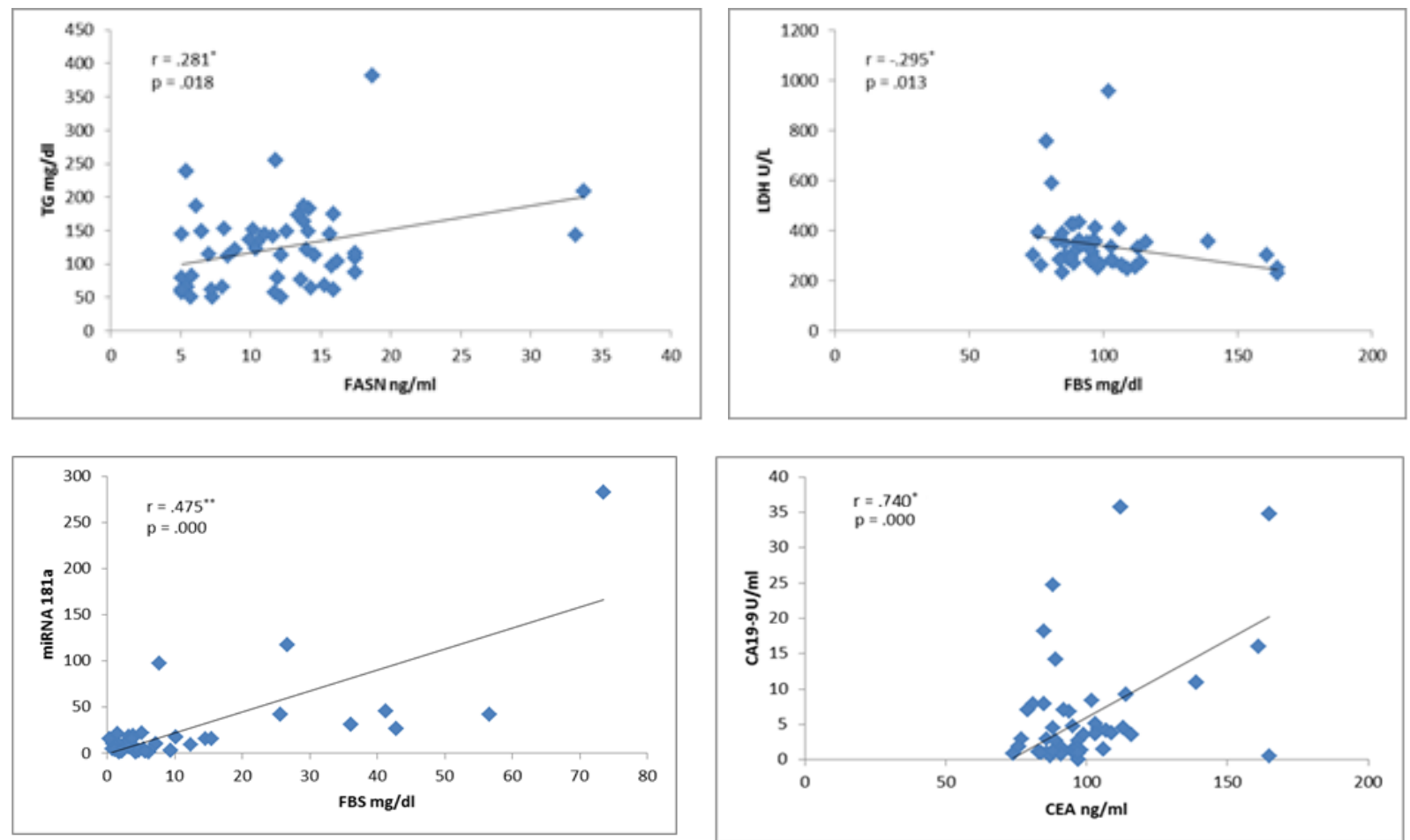

Figure (2): Corre lation analysis of some studied parameters

Table (2): Clinicopathological Characteristics of patients $(n=70)$

\begin{tabular}{|c|c|c|}
\hline \multirow{2}{*}{$\begin{array}{c}\text { Tumour location } \\
\text { n }(\%)\end{array}$} & Colon & $47(67.1 \%)$ \\
\hline & Rectum & $23(32.9 \%)$ \\
\hline \multirow{6}{*}{$\begin{array}{c}\text { Tumour Stage } \\
\text { n }(\%)\end{array}$} & & \\
\hline & Stage I & $36(51.4 \%)$ \\
\hline & Stage IIa & $10(14.3 \%)$ \\
\hline & Stage IIb & $9(12.9 \%)$ \\
\hline & Stage III & $11(15.7 \%)$ \\
\hline & Stage IV & $4(5.7 \%)$ \\
\hline \multirow{4}{*}{$\begin{array}{c}\text { Tumour Grade } \\
\text { n }(\%)\end{array}$} & & \\
\hline & G1 & $14(20.0 \%)$ \\
\hline & G2 & $42(60.0 \%)$ \\
\hline & G3 & $14(20.0 \%)$ \\
\hline
\end{tabular}

Table (3): Statistical analysis of the studied parameters according to gender and tumour location

\begin{tabular}{|c|c|c|c|c|c|c|}
\hline \multirow[t]{2}{*}{ Parameter } & \multirow{2}{*}{$\begin{array}{c}\text { Control } \\
(n=30)\end{array}$} & \multirow{2}{*}{$\begin{array}{c}\text { Patients } \\
(n=70)\end{array}$} & \multicolumn{2}{|c|}{ GENDER } & \multicolumn{2}{|c|}{ TUMOR LOCATION } \\
\hline & & & Male $(n=30)$ & Female $(n=40)$ & Colon $(n=47)$ & $\operatorname{Rectum}(n=23)$ \\
\hline $\begin{array}{l}\text { CEA }^{\#} \\
\text { ng/ml }\end{array}$ & $\begin{array}{c}1.85-2.78 \\
(1.96)\end{array}$ & $\begin{array}{l}2.7-20.9 \\
(5.90) *\end{array}$ & $\begin{array}{c}3.1-29.7 \\
(9.45)\end{array}$ & $\begin{array}{c}2.7-17.1 \\
(3.60)\end{array}$ & $\begin{array}{c}3.4-22.5 \\
(7.75)\end{array}$ & $\begin{array}{c}3.47-22.9 \\
(5.44)\end{array}$ \\
\hline $\begin{array}{c}\text { CA19-9 }^{\#} \\
\text { U/ml }\end{array}$ & $\begin{array}{c}3.88-6.39 \\
(5.50)\end{array}$ & $\begin{array}{l}6.9-49.6 \\
(15.30)^{*}\end{array}$ & $\begin{array}{c}14.2-87.7 \\
(16.9)^{\$}\end{array}$ & $\begin{array}{c}12.0-28.0 \\
(15.3)\end{array}$ & $\begin{array}{c}13.2-53.2 \\
(15.4)\end{array}$ & $\begin{array}{c}2.41-64.5 \\
(10.20)\end{array}$ \\
\hline $\begin{array}{l}\text { FASN } \\
\mathrm{ng} / \mathrm{ml}\end{array}$ & $\begin{array}{c}5.88-7.23 \\
(5.9)\end{array}$ & $\begin{array}{c}13.2-16.2 \\
(13.9)^{*}\end{array}$ & $\begin{array}{c}13.37-19.87 \\
(14.25)^{\$}\end{array}$ & $\begin{array}{l}12.2-14.43 \\
\quad(13.4)\end{array}$ & $\begin{array}{c}13.3-17.6 \\
(14.0)\end{array}$ & $\begin{array}{c}11.48-14.91 \\
(13.8)\end{array}$ \\
\hline$\underset{\mathbf{U} / \mathbf{L}}{\mathbf{L D H}^{\#}}$ & $\begin{array}{c}324.0-360.0 \\
(353.0)\end{array}$ & $\begin{array}{c}302.9-376.4 \\
(301.5)\end{array}$ & $\begin{array}{c}267.1-336.8 \\
(279.0)\end{array}$ & $\begin{array}{c}309.6-426.3 \\
(331.0)\end{array}$ & $\begin{array}{c}296.2-384.9 \\
(303.0)\end{array}$ & $\begin{array}{c}267.0-409.5 \\
(291.0)\end{array}$ \\
\hline$\underset{181 a^{\#}}{\operatorname{miRNA}}$ & $\begin{array}{c}0.86-1.37 \\
(1.03)\end{array}$ & $\begin{array}{l}2.56-10.78 \\
(4.38) *\end{array}$ & $\begin{array}{l}3.2-5.33 \\
(3.89)^{\$}\end{array}$ & $\begin{array}{c}4.8-15.3 \\
(6.07)\end{array}$ & $\begin{array}{c}3.14-9.2 \\
(4.08)\end{array}$ & $\begin{array}{c}5.0-17.3 \\
(7.01)\end{array}$ \\
\hline
\end{tabular}

${ }^{\#}$ Values are presented as Interquartile Range IQR and (median) $; * \overline{\text { significant difference as compared with control } \mathrm{P} \leq}$ $0.05 ;{ }^{\$}$ significant difference as compared with females $\mathrm{P} \leq 0.05$. 
Table (4): Parameter levels at different tumour stages

\begin{tabular}{|c|c|c|c|c|c|c|}
\hline \multirow{2}{*}{ Parame ter } & \multicolumn{5}{|c|}{ STAGE } \\
\cline { 2 - 7 } & Control & I & IIa & IIb & III & IV \\
\hline CEA & $1.85-2.78$ & $9.88-26.7$ & $4.17-12.7$ & $8.08-50.6$ & $1.78-5.7$ & $0.71-1.96$ \\
ng/ml & $(1.96)^{\mathrm{a}}$ & $(8.97)^{\mathrm{b}}$ & $(9.45)^{\mathrm{b}}$ & $(42.8)^{\mathrm{c}}$ & $(3.69)^{\mathrm{a}}$ & $(1.49)^{\mathrm{a}}$ \\
\hline CA19-9 & $3.88-6.39$ & $12.6-82.8$ & $3.7-14.8$ & $4.05-34.6$ & $5.47-14.6$ & $8.4-28.1$ \\
U/ml & $(5.50)^{\mathrm{a}}$ & $(17.6)^{\mathrm{b}}$ & $(9.45)^{\mathrm{a}}$ & $(26.5)^{\mathrm{b}}$ & $(10.2)^{\mathrm{a}}$ & $(20.6)^{\mathrm{b}}$ \\
\hline FASN & $5.88-7.23$ & $12.2-15.7$ & $11.54-28.8$ & $13.0-16.7$ & $9.8-15.1$ & $9.9-17.5$ \\
ng/ml & $(5.9)^{\mathrm{a}}$ & $(13.4)^{\mathrm{b}}$ & $(17.45)^{\mathrm{c}}$ & $(13.8)^{\mathrm{b}}$ & $(11.8)^{\mathrm{b}}$ & $(14.6)^{\mathrm{b}}$ \\
\hline LDH U/L & $324.0-360.0$ & $244.6-337.2$ & $228.1-279$ & $238.5-408.6$ & $274.2-369.0$ & $596.4-1016.0$ \\
& $(353.0)^{\mathrm{a}}$ & $(285.0)^{\mathrm{b}}$ & $(246.0)^{\mathrm{b}}$ & $(355.0)^{\mathrm{a}}$ & $(325.0)^{\mathrm{a}}$ & $(756.0)^{\mathrm{c}}$ \\
\hline miRNA & $0.86-1.37$ & $3.2-5.3$ & $0.14-8.9$ & $2.4-12.15$ & $5.0-26.6$ & $21.8-42.7$ \\
181a & $(1.03)^{\mathrm{a}}$ & $(3.66)^{\mathrm{b}}$ & $(2.03)^{\mathrm{b}}$ & $(7.01)^{\mathrm{c}}$ & $(10.93)^{\mathrm{c}}$ & $(34.78)^{\mathrm{d}}$ \\
\cline { 3 - 8 }
\end{tabular}

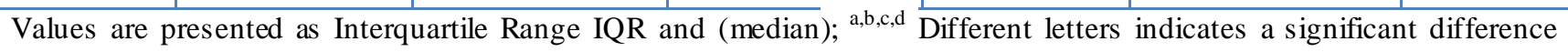
between the two groups.

Table (5): Parameter levels at different tumour grades

\begin{tabular}{|c|c|c|c|c|}
\hline \multirow[t]{2}{*}{ Parameter } & \multirow[t]{2}{*}{ Control } & \multicolumn{3}{|c|}{ GRADE } \\
\hline & & G1 & G2 & G3 \\
\hline $\begin{array}{c}\text { CEA } \\
\text { ng/ml }\end{array}$ & $\begin{array}{c}1.85-2.78 \\
(1.96)^{\mathrm{a}}\end{array}$ & $\begin{array}{c}0.225-5.19 \\
(1.72)^{\mathrm{a}}\end{array}$ & $\begin{array}{c}13.3-27.9 \\
(10.2)^{\mathrm{b}}\end{array}$ & $\begin{array}{l}2.44-23.9^{c} \\
(3.69)\end{array}$ \\
\hline $\begin{array}{c}\text { CA19-9 } \\
\text { U/ml }\end{array}$ & $\begin{array}{c}3.88-6.39 \\
(5.50)^{\mathrm{a}}\end{array}$ & $\begin{array}{l}3.3-12.6 \\
(4.55)^{b}\end{array}$ & $\begin{array}{c}21.0-36.9 \\
(17.6)^{c}\end{array}$ & $\begin{array}{l}7.6-24.9 \\
(15.3)^{d}\end{array}$ \\
\hline $\begin{array}{l}\text { FASN } \\
\text { ng/ml }\end{array}$ & $\begin{array}{c}5.88-7.23 \\
(5.9)^{\mathrm{a}}\end{array}$ & $\begin{array}{l}8.6-17.7 \\
(12.9)^{\mathrm{b}}\end{array}$ & $\begin{array}{c}13.6-17.8 \\
(14.8)^{\mathrm{b}}\end{array}$ & $\begin{array}{c}11.27-15.3 \\
(13.8)^{\mathrm{b}}\end{array}$ \\
\hline $\begin{array}{c}\text { LDH } \\
\text { U/L }\end{array}$ & $\begin{array}{c}324.0-360.0 \\
(353.0)^{\mathrm{a}}\end{array}$ & $\begin{array}{c}262.9-513.6 \\
(355.5)^{\mathrm{a}}\end{array}$ & $\begin{array}{c}268.6-326.4 \\
(282.5)^{\mathrm{a}}\end{array}$ & $\begin{array}{c}251.13-530.4 \\
(360.0)^{\mathrm{b}}\end{array}$ \\
\hline $\begin{array}{c}\text { miRNA } \\
181 a\end{array}$ & $\begin{array}{c}0.86-1.37 \\
(1.03)^{\mathrm{a}}\end{array}$ & $\begin{array}{l}1.17-10 \\
(1.82)^{b}\end{array}$ & $\begin{array}{l}3.5-5.9 \\
(3.71)^{b}\end{array}$ & $\begin{array}{c}12.1-30.1 \\
(17.1)^{\mathrm{c}}\end{array}$ \\
\hline
\end{tabular}

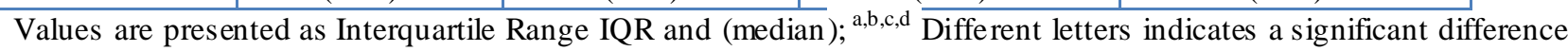
between the two groups.

Table (6): Diagnostic sensitivity, specificity and accuracy for studied parameters

\begin{tabular}{|c|c|c|c|c|c|c|c|c|}
\hline \multirow[t]{2}{*}{ Parameter } & \multirow[t]{2}{*}{$\mathbf{A U} \mathbf{C}^{\#}$} & \multirow[t]{2}{*}{$P$ value } & \multicolumn{2}{|c|}{$\begin{array}{c}\text { Asymptotic } \\
95 \% \text { CI }\end{array}$} & \multirow{2}{*}{$\begin{array}{c}\text { Cut } \\
\text { off } \\
\text { valu } \\
\text { e }\end{array}$} & \multirow[t]{2}{*}{$\begin{array}{c}\text { Sensitivity } \\
\%\end{array}$} & \multirow[t]{2}{*}{$\begin{array}{c}\text { Specificity } \\
\%\end{array}$} & \multirow{2}{*}{$\begin{array}{c}\text { Accurac } \\
\mathbf{y} \\
\%\end{array}$} \\
\hline & & & $\begin{array}{l}\text { Lower } \\
\text { Bound }\end{array}$ & $\begin{array}{l}\text { Upper } \\
\text { Bound }\end{array}$ & & & & \\
\hline CEA (ng/ml) & 0.832 & 0.0001 & 0.637 & 0.827 & 2.9 & 90 & 85 & 88 \\
\hline CA19-9 (U/ml) & 0.865 & 0.0001 & 0.674 & 0.856 & 10.0 & 92 & 88 & 90 \\
\hline FASN (ng/ml) & 0.957 & 0.0001 & 0.920 & 0.995 & 8.2 & 96 & 95 & 95 \\
\hline miRNA 181a & 0.912 & 0.0001 & 0.857 & 0.967 & 2.00 & 95 & 90 & 92 \\
\hline
\end{tabular}

\# Area under the curve; CI, confidence interval.

\section{Discussion:}

The clinical value of early diagnosis of cancer has been discussed as early as 1933 by Dr. J.S. Mceachern who emphasized the importance of applying "accurate diagnostic measures" for confirming the presence of cancer at early stages (30). Nowadays, it is confirmed that the cancer stage at the time of diagnosis clearly influence the mortality rates, as was demonstrated in CRC by the $93 \%$ and $16 \%$ three years survival rates of early diagnosed stage I and IV patients, respectively (31). The delay in diagnosis; therefore, treatment of CRC is a multi-factorial problem (32). Unfortunately, lack of highly specific and sensitive tumour 
markers for CRC remains a major obstacle toward highly successful diagnosis and therapy (8). Our current study evaluated the diagnostic value of standard tumour markers such as CEA and CA19-9 as well as the metabolic mediators FASN, LDH and miR-181a; moreover, assessing their potential association with CRC stage and grade.

Long chain fatty acids synthesized by FASN are required at high levels in cancer cells for membrane assembly and as a source of stored energy in the case of excess carbohydrates through $\beta$-oxidation of triacylglycerols $(33,34)$. Our data demonstrated that both FASN and TG levels were higher in sera of CRC patients compared to healthy controls. This significant increase in FASN was detected starting from early stage-I tumour and continued through all stages. Therefore, the elevated serum FASN levels detected in our study confirms an increased lipogenic metabolic status in CRC patients. The association between high FASN levels and insulin resistance which leads to higher FBS was previously reported (35), this relation explains our data showing a significant increase in FBS levels in patients compared with control subjects. Our data also revealed a modest association between FBS and TG levels with CRC.

Coordinated elevation of lipogenic and glycolytic enzymes in human carcinoma was previously reported (36), among these glycolytic enzymes is the $\mathrm{LDH}$ enzyme which plays a tumour promoting role through a C-MYC mediated cell transformation pathway (37). Our data presented in this paper showed a highly significant difference of serum LDH levels only in stage IV patients compared with stages I, II and III as well as control subjects. Our results are in accordance with other data reporting no significant difference in serum
LDH levels between CRC or gastric cancer patients and controls, except between stage IV CRC and control (38-40). Moreover, it has reported that only $50 \%$ of confirmed CRC cases show increasing tissue LDH activity (41). The relation between the overall serum LDH level and clinicopathological status of CRC is controversial and further studies need to be performed, as some reports show significant relation with tumour stages, while others denies this finding $(39,42)$. Our data confirms the low serum $\mathrm{LDH}$ diagnostic sensitivity at early stages, it may also point to the value of $\mathrm{LDH}$ as a marker for advanced stage CRC.

miRNAs influence normal and cancer cellular metabolism by regulating genes whose protein products are direct regulators of metabolism or modulate the expression of metabolic enzymes $(43,44)$. miR-181a reprograms the metabolism of colon cells by increasing glucose uptake and lactate secretion required for increased cancer cell proliferation (45). In addition to its metabolic reprogramming effect, miR-181a is also suggested to promote the epithelial-mesenchymal transition and repression of the tumour suppressor WIF-1gene (46). In accordance with a pro-cancerous role for miR-181a, the present study shows a progressive stage and grade-associated highly significant elevated levels of miR-181a in CRC patients compared to control subjects.

\section{Conclusion:}

Our diagnostic accuracy comparative analys is revealed that serum FASN had the highest sensitivity and specificity (96\% and 95\%) respectively, followed by plasma miR-181a (95\% and $92 \%$ ), both markers were superior to $\mathrm{LDH}$, CEA and CA-19-9, miR-181a had the best 
association with stage and grade compared to all other markers.

Finally, it worth mentioning that our data might concur and disagree with other reports, we believe that these discrepancies might be attributed to the patient's individual biological differences, pathological staging and grading variation and the sample size effect or all combined together. Therefore, further studies including more number of patients with more restricted clinicopathological classification need to be performed.

\section{References:}

1. Siegel RL, Miller KD, Jemal A. Cancer statistics, 2015. CA: A Cancer Journal For Clinicians. 1;65(1):5-29, Jan 2015 .

2. Jemal A, Center MM, DeSantis C, Ward EM. Global patterns of cancer incidence and mortality rates and trends. Cancer Epidemiology and Prevention Biomarkers. 1;19(8):1893-907, Aug 2010.

\section{Fe rlay J, Soe rjomataram I, Dikshit R, Eser S,} Mathers C, Rebelo M, Parkin DM, Forman D, B ray F. Cancer incidence and mortality worldwide: sources, methods and major patterns in GLOBOCAN 2012. International journal of cancer. 1;136(5):E359-86 Mar 2015,

4. Beck DE. The importance of colorectal cancer screening. The Ochsner Journal.;15(1):11-2 Mar 2015 ,

5. Meyerhardt JA, Mayer RJ. Systemic therapy for colorectal cancer. New England Journal of Medicine. 3;352(5):476-87 Feb 2005,.

6. Phan LM, Yeung SC, Lee MH. Cancer metabolic reprogramming: importance, main features, and potentials for precise targeted anti- cancer therapies. Cancer biology \& medicine.;11(1):1-9, 2014 .

7. Stojkovic LM, Stankovic S, Stojkovic M, Markovic V, Dimitrije vic I, Lalosevic J, Petrovic J, Brankovic M, Pavlovic MA, Krivokapic $Z$. Can preoperative CEA and CA19-9 serum concentrations suggest metastatic disease in colorectal cancer patients?. Hellenic journal of nuclear medicine.;20(1):41, 2017.

8. Vega P, Valentín F, Cubiella J. Colorectal cancer diagnosis: Pitfalls and opportunities. World journal of gastrointestinal oncology.;7(12):422-33, Dec 2015.

9. Zhang F, Zhang Y, Zhao W, Deng K, Wang Z, Yang C, Ma L, Openkova MS, Hou Y, Li K. Metabolomics for biomarker discovery in the diagnosis, prognosis, survival and recurrence of colorectal cancer: a systematic review. Oncotarget. 23;8(21):35460, May2017 .

10. Warburg O. On respiratory impairment in cancer cells. Science. 10;124(3215):269-70, Aug 1956.

11. Christofk HR, Vander Heiden MG, Harris MH, Ramanathan A, Gerszten RE, Wei R, Fleming MD, Schreiber SL, Cantley LC. The M2 splice isoform of pyruvate kinase is important for cancer metabolism and tumour growth. Nature. 13;452(7184):230-3, Mar 2008 .

12. Diaz-Ruiz R, Rigoulet M, Devin A. The Warburg and Crabtree effects: on the origin of cancer cell energy metabolism and of yeast glucose repression. Biochimica et Biophysica Acta (BBA)Bioenergetics. 30;1807(6):568-76, Jun 2011.

13. Fischer K, Hoffimann P, Voelkl S, Meidenbauer N, Ammer J, EdingerM, Gottfried E, Schwarz S, Rothe G, Hoves S, Renner K. Inhibitory effect of tumor cell-derived lactic acid 
on human T cells. Blood. 1;109(9):3812-9, May 2007.

14. Baumann F, Leukel P, Doe rfe It A, Beier CP, Dettmer K, Oefiner PJ, Kas tenberger M, Kre utz M, Nickl-Jockschat T, Bogdahn U, Bosse rhoff AK. Lactate promotes glioma migration by TGF$\beta 2$-dependent regulation of matrix metalloproteinase-2. Neuro-oncology. 1;11(4):36880, Aug 2009 .

15. Mashima T, Seimiya H, Tsuruo T. De novo fatty-acid synthesis and related pathways as molecular targets for cancer therapy. British journal of cancer. 5;100(9):1369-72, May 2009 .

16. Walter K, Hong SM, Nyhan S, Canto M, Fedarko N, Klein A, Griffith M, Omura N, Medghalchi S, Kuhajda F, Goggins M. Serum fatty acid synthase as a marker of pancreatic neoplasia. Cancer Epidemiology and Prevention Biomarkers. 1;18(9):2380-5, Sep 2009.

17. Vazquez-Martin A, Colomer R, Brunet J, Lupu R, Menendez JA. Overexpression of fatty acid synthase gene activates HER1/HER2 tyrosine kinase receptors in human breast epithelial cells. Cell proliferation 1;41(1):59-85, . Feb 2008.

18. Notarnicola $\mathbf{M}$, Tutino $\mathbf{V}$, Calvani $\mathbf{M}$, Lorusso D, Guerra V, Caruso MG. Serum levels of fatty acid synthase in colorectal cancer patients are associated with tumor stage. Journal of gastrointestinal cancer. 1;43(3):508-11, Sep 2012 .

19. Menendez JA, Lupu R. Fatty acid synthase and the lipogenic phenotype in cancer pathogenesis. Nature Reviews Cancer. 1;7(10):763-77, Oct 2007. 20. Cowey S, Hardy RW. The metabolic syndrome: a high-risk state for cancer?. The American journal of pathology. 30;169(5):1505-22, Nov 2006.
21. García-Jiménez C, García-Martínez JM, Chocarro-Calvo A, De la Vieja A. A new link between diabetes and cancer: enhanced WNT/ $\beta$ catenin signaling by high glucose. Journal of molecular endocrinology. 1;52(1):R51-66, Feb 2014

22. Wuermli L, Joerger M, Henz S, Schmid HP, Riesen WF, Thomas G, Krek W, Cerny T, Gillessen S. Hypertriglyceridemia as a possible risk factor for prostate cancer. Prostate cancer and prostatic diseases. 1;8(4):316-20, Dec 2005.

23. Peng Y, Croce CM. The role of MicroRNAs in human cancer. Signal Transduction and Targeted Therapy. 28;1:15004, Jan 2016.

24. Gao W, Yu Y, Cao H, Shen H, Li X, Pan S, Shu Y. Deregulated expression of miR-21, miR143 and miR-181a in non small cell lung cancer is related to clinicopathologic characteristics or patient prognosis. Biomedicine \& Pharmacotherapy. 31;64(6):399-408, Ju1 2010.

25. Li L, Xu QH, Dong YH, Li GX, Yang L, Wang LW, Li HY. MiR-181a upregulation is associated with epithelial-to-mesenchymal transition (EMT) and multidrug resistance (MDR) of ovarian cancer cells. Eur Rev Med Pharmacol Sci. 1;20(10):2004-10, May 2016.

26. Taylor MA, Sossey-Alaoui K, Thompson CL, Danielpour D, Schiemann WP. TGF- $\beta$ upregulates miR-181a expression to promote breast cancer metastasis. The Journal of clinical investigation. 2;123(1):150-63, Jan 2013 .

27. Ji D, Chen Z, Li M, Zhan T, Yao Y, Zhang Z, Xi J, Yan L, Gu J. MicroRNA-181a promotes tumor growth and liver metastasis in colorectal cancer by targeting the tumor suppressor WIF-1. Molecular cancer. 23;13(1):86, Apr 2014. 
28. Wei Z, Cui L, Mei Z, Liu M, Zhang D. miR-181a mediates metabolic shift in colon cancer cells via the PTEN/AKT pathway. FEBS letters. 2;588(9):1773-9, May 2014.

29. Livak KJ, Schmittgen TD. Analysis of relative gene expression data using real-time quantitative PCR and the 2- $\Delta \Delta \mathrm{CT}$ method. methods. 1;25(4):402-8, Dec 2001.

30. Mceachern JS. The importance of early diagnosis in cancer. Can Med Assoc J.; 28(5): 540541, May 1933 .

31. Ciccolallo L, Capocaccia R, Coleman MP, Berrino F, Coebergh JW, Damhuis RA, Faivre J, Martinez-Garcia C, Møller H, de Leon MP, Launoy G. Survival differences between European and US patients with colorectal cancer: role of stage at diagnosis and surgery. Gut. 1;54(2):268-73, Feb 2005 .

32. Langenbach MR, Schmidt J, Neumann J, Zirngibl H. Delay in treatment of colorectal cancer: multifactorial problem. World journal of surgery. 21;27(3):304-8, Mar 2003 .

33. Wang H, Xi Q, Wu G. Fatty acid synthase regulates invasion and metastasis of colorectal cancer via Wnt signaling pathway. Cancer Med. ;5(7):1599-606. 2016.

34. Röhrig F, Schulze A. The multifaceted roles of fatty acid synthesis in cancer. Nature Reviews Cancer. 1;16(11):732-49, Nov 2016.

35. Fernandez-Real JM, Menendez JA, MorenoNavarrete JM, Blüher M, Vazquez-Martin A, Vázquez MJ, Ortega F, Diéguez C, Frühbeck G, Ricart W, Vidal-Puig A. Extracellular fatty acid synthase: a possible surrogate biomarker of insulin resistance. Diabetes. 1;59(6):1506-11, Jun 2010 .

36. Szutowicz A, Kwiatkowski JA, Angielski S. Lipogenetic and glycolytic enzyme activities in carcinoma and nonmalignant diseases of the human breast. British journal of cancer.;39(6):681,Jun 1979.

37. Koukourakis MI, Giatromanolaki A, Harris AL, Sivridis E. Comparison of metabolic pathways between cancer cells and stromal cells in colorectal carcinomas: a metabolic survival role for tumorassociated stroma. Cancer research. 15;66(2):6327, Jan 2006 .

38. Kostakis ID, Vaiopoulos AG, Philippou A, Papavassiliou AG, Koutsilie ris M, Kouraklis G. Preoperative serum lactate dehydrogenase levels in colorectal and gastric cancer: a hospital-based case-control study. Biomarkers in medicine.;7(1):131-7, Feb 2013.

39. Celik S, Yılmaz ME, Bilgiç B. Analys is of the Relationship between the Levels of Carcinoembryonic Antigen and Lactate Dehydrogenase, and the Neutrophil/Lymphocyte Ratio in Colorectal Cancer. Immunochem Immunopathol;2(119):2, . 2016.

40. Caputo D, Caricato M, Vincenzi B, La Vaccara V, Mascianà G, Coppola R. Serum lactate dehydrogenase alone is not a helpful prognostic factor in resected colorectal cancer patients. Updates in surgery. 1;66(3):211-5, Sep 2014 .

41. Lawson MJ, White LM, Coyle P, Butler RN, Roberts-Thomson IC, Conyers RA. An assessment of proliferative and enzyme activity in transitional mucosa adjacent to colonic cancer. Cancer. 1;64(5):1061-6, Sep 1989.

42. Koukourakis MI, Giatromanolaki A, Sivridis

E. Colorectal cancer: Lactate dehydrogenase 
(LDH) activity as a prognostic marker. Colorectal cancer.:241-53, 2009.

43. Vienberg S, Geiger J, Madsen S, Dalgaard

LT. MicroRNAs in metabolism. Acta physiologica. 1;219(2):346-61, Feb 2017.

44. Chan B, Manley J, Lee J, Singh SR. The emerging roles of microRNAs in cancer metabolism. Cancer letters 28;356(2):301-8, . Jan 2015.

45. Wei Z, Cui L, Mei Z, Liu M, Zhang D. miR-181a mediates metabolic shift in colon cancer cells via the PTEN/AKT pathway. FEBS letters. 2;588(9):1773-9, May 2014.

\section{Ji D, Chen Z, Li M, Zhan T, Yao Y, Zhang}

Z, Xi J, Yan L, Gu J. MicroRNA-181a promotes

tumor growth and liver metastasis in colorectal cancer by targeting the tumor suppressor WIF-1.

Molecular cancer. 23;13(1):86, Apr 2014. 